\title{
Analisis Kerusakan Trim Air Pressure Regulating and Shutoff Valve Pada Pesawat Boeing 737-800 Menggunakan Metode Failure Mode and Effect Analysis (FMEA)
}

\author{
Rizwan Maulana Hanif(1)*, Freddy Franciscus(2), Mufti Arifin ${ }^{(3)}$ \\ (1)(2)(3) Prodi Teknik Penerbangan, Fakultas Teknologi Kedirgantaraan, Universitas \\ Suryadarma Komplek Bandara Halim Perdanakusuma, Jakarta 13610, Indonesia \\ * Corresponding Author: rizwanmaulana01@gmail.com
}

\begin{abstract}
Air Conditioning (AC) is the one of system in aircraft to make a passanger and all cabin crew comfortable. Trim Air Pressure Regulating and Shutoff Valve or also known as Trim Air PRSOV is a component on the Boeing 737-800 aircraft to regulate flow of hot air constantly before entering the aircraft cabin. Refering to the data for the last 6 years, the replacement of the component belonging to one of the Indonesian national flight carrier using Boeing 737-800 aircraft was the occurance of 84 times the cooling system failure which caused the light indiacator in the cockpit to light up. Among them happened 70 times unscheduled maintenance and 14 times scheduled maintenance. Thus, this essay was made to analyze the causes of the damage that occurred to the Trim Air PRSOV. The method used in this research is Failure Mode and Effect Analysis (FMEA) is the technique used to find, identify and eliminate failures or damage to a system or process. The first step is to analyze using a Pareto diagram and then continue with the FMEA method so that an analysis of the damage that often occurs is damage to the diaphragm with $42 \%$ damage with an RPN value of 389.1, erosion on the ring seal with $22 \%$ damage with an RPN value of 376 and shaft seal damaged with $12 \%$ damage with an RPN value of 295.1 for it requires aggressive treatment. Therefore, repairs with a long TAT of 14 days are expected to increase the reliability of the PRSOV Trim Pressure component. For this reason, repairs are carried out with a long TAT of 14 days, it is hoped that there will be an increase in the reliability of the PRSOV Trim Pressure componen
\end{abstract}

Keywords : Trim Air Pressure Regulating and ShuttOff Valve, Boeing 737-800, Pareto Diagram, Failure Mode and Effect Analysis (FMEA). 


\section{Pendahuluan}

Pesawat udara merupakan moda tranportasi yang banyak diminati saat ini dikarenakan dapat mempersingkat waktu perjalanan. Selain mempersingkat waktu, pesawat merupakan moda tranportasi yang aman dan nyaman. Dengan penggunaannya yang semakin meningkat pesawat perlu dilakukan pengecekan dengan regulasi untuk kelaikan pesawat. Untuk itu dilakukan pemeliharaan dan perawatan dalam menunjang faktor kenyamanan dan keselamatan.

Pesawat terbang memiliki beberapa sistem yang digunakan dalam operasional pesawat udara. Salah satu sistem yang banyak digunakan pesawat terbang adalah sistem pneumatik. Sistem pnuematik akan menghasilkan udara bertekanan dan udara panas yang digunakan oleh sistem starting engine, air conditioning, cabin pressurization, dan sistem lainnya. Sistem pnuematik yang digunakan pada air conditioning pesawat dibutuhkan tekanan dan suhu yang konstan untuk kenyamanan penumpang berserta awak kabin. Untuk itu dibutuhkan suatu komponen untuk menjaga tekanan dan suhu tetap konstan, salah satunya komponen tersebut adalah Trim Air. Pressure Regulating and Shutoff Valve (Trim Air PRSOV).

Dalam rentang waktu 6 tahun terakhir pesawat Boeing 737-800 milik salah satu maskapai nasional Indonesia terjadi 84 kerusakan pada komponen tersebut. 14 kerusakan terjadi pada saat schedule maintenance sedangkan 70 kerusakan terjadi saat unshedule maintenance. Sehingga perlu dianalisa mengapa komponen tersebut rusak sebelum schedule maintenance yang mengakibatkan cost pada airlane dikarenakan terjadinya delay disebabkan oleh pesawat gagal atau tidak dapat terbang.

Perawatan pesawat udara adalah kegiatan untuk menjaga dan memelihara agar pesawat yang digunakan dapat berfungsi dengan baik dan dapat digunakan. Dalam melakukanperawatan dibutuhkan manajemen untuk mengatur jalannya perawatan. Manjemen perawatan meruapakan suatu konsep yang mengatur operasi dalam perawatan untuk menentukan terjadinyaperawatan. Hal ini bertujuan untuk mengurangi kerusakan yang terjadi secara mendadak atau tiba-tiba. Adapun jenis-jenis perawatanterbagi menjadi 2 yaitu perawatan yang terencana (planned maintenance) dan perawatan yang tidak terencana (unplanned maintenance).

Air Conditioning (AC) berfungsi untuk mengendalikan suhu ruang dan tekanan di dalam pesawat. AC salah satu sistem untuk membuat penumpang merasa nyaman di dalam pesawat terbang. Ketinggian jelajah umum pesawat

Pada prinsipnya sistem ini meningkatkan tekanan dengan mengkompresikan udara luar pesawat menggunakan kompresor gas turbin. Udara bertekanan dengan temperatur yang tinggi kemudian disalurkan melewati penukar panas yang didinginkan oleh udara luar pada kondisi ketinggian yang memiliki suhu dingin. Kemudian, udara yang telah digabungkan akan diekspansikan pada turbin terlebih dahulu baru kemudian disalurkan kedalam pesawat.

terbang adalah sekitar 30.000 kaki diatas permukaan tanah. Pada ketinggian tersebut, terjadi penurunan suhu serta tekanan udara yang sangat signifikan. Dengan besarnya penurunan tersebut, dibutuhkan suatu sistem yang berfungsi untuk mengendalikan suhu dan tekanan agar penumpang dapat merasa 
aman dannyaman ketika berada di dalam pesawatterbang.

Trim Air PRSOV merupakan komponen untuk menkontrol aliran dan tekanan udara ke zona trim air modulating valves. Untuk pesawat Boeing 737-800 terdapat 1 buah Trim Air PRSOV yang letaknya berada di kanan air conditioning comparment. Trim Air PRSOV bekerja dengan cara membuka dan menutup katup dengan sistem butterfly-type valve. Valve ditahan dengan spring yang bekerja normal dalam kondisi posisi tertutup. Trim air PRSOV dikontrol secara elektrik dan digerakkan secara pneumatic.

\subsection{Tujuan Penelitian}

1. Mengetahui modus utama kegagalan yang terjadi pada Trim Pressure Regulating and Shutoff Valve pada pesawat Boeing 737-800.

2. Mengetahui RPN dari modus kegagalan utama kerusakan Trim pressure Regulating and Shutoff Valve pada pesawat Boeing 737800.

3. Mengetahui hubungan modus kegagalan dengan Turn Around Time (TAT) pada Trim Air Pressure Regulating and Shutoff Valve.

\section{Metode Penelitian}
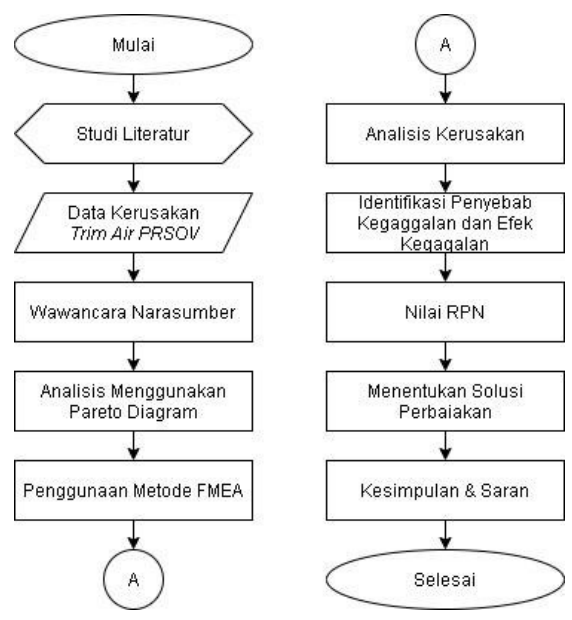

Gambar 1. Diagram alur Penelitian
Proses dimulai dengan mengidentifikasi masalah yang akan dijadikan topik dalam penilitian dengan cara mencari kerusakan yang sering terjadi pada pesawat Boeing 737-800 yang menyebabkan pesawat delay nya pesawat. Setelah itu akan ditentukan tujuan yang ingin dicapai agar mengetahui penyebab kerusakan yang dialami dan dapat menguranginya. Langkah selanjutnya adalah mencari literatur - literatur terkait dengan Trim Air PRSOV serta metode yang akan digunakan. Literatur yang telah didapat akan dikaji serta diobservasi untuk selanjutnya akan diolah dan dianalisis menggunakan metode FMEA. Langkah yang dilakukan yaitu menganalisis menggunakan metode pareto diagram sehingga didapatkan persentase kerusakan yang sering terjadi sehingga mendapatkan modus utama kegagalan. Kemudian dilakukan analisis menggunakan metode FMEA sehingga mendapatkan nilai RPN dengan melaksanakan kuesioner, kemudiandapat ditentukan bahwa kerusakan yang terjadi masuk dalam kategori yang agresif atau tidak. Untuk itu didapatkan solusi perbaikan yang dapat diterapkan kedalam proses perawatan Trim Air PRSOV dan dapat mengurangi kerusakan yang terjadi. Adapun spesifikasi Trim Air PRSOVdapat dilihat pada table 1 berikut: 
Jurnal Teknologi Kedirgantaraan, Vol, VII No. 1, Januari 2022, P-ISSN 2528-2778, E-ISSN 2684-9704 https://doi.org/ 10.35894/jtk.v7i1

Tabel 1. Spesifikasi Trim Air PRSOV Honeywell

\begin{tabular}{|c|c|}
\hline Characteristic & Spesificatian \\
\hline \multicolumn{2}{|l|}{ Dimensian } \\
\hline Length & 8.5 inches $(216 \mathrm{~mm})$ apprax. \\
\hline Width & 6.75 inches $(171.5 \mathrm{~mm})$ apprax. \\
\hline Height & 10.1 inches $(256.5 \mathrm{~mm})$ apprax. \\
\hline Weight & 6.25 paunds $(2.835 \mathrm{~kg})$ maximum \\
\hline \multicolumn{2}{|l|}{ Temperature range } \\
\hline Ambient & 65 ta $200=F(-54$ ta $93 \circ \mathrm{C})$ \\
\hline \multicolumn{2}{|l|}{ Pressure range } \\
\hline Ambient & $2.45 \mathrm{ta} 15.5 \mathrm{PSIA}(16.905 \mathrm{ta} 106.95 \mathrm{kPa})$ \\
\hline Current & 1.0 ampere at $80^{\circ} \mathrm{F}\left(27^{\circ} \mathrm{C}\right)$ and $28 \mathrm{VDC}$ \\
\hline Operatianal & $\begin{array}{l}45.0 \text { PSIG }(207 \mathrm{kPa}) \text { at } 407^{\circ} \mathrm{F}\left(208^{\circ} \mathrm{C}\right) \\
\text { maximum }\end{array}$ \\
\hline Regulating & $\begin{array}{l}3.0 \text { ta } 5.0 \text { PSIG (20.7 ta } 34.5 \mathrm{kPa} \text { ) ab ave } \\
\text { cabin pressure at inlet pressure of } 10 \text { ta } 50 \\
\text { PSIG (69 ta } 345 \mathrm{kPa} \text { ) }\end{array}$ \\
\hline \multicolumn{2}{|l|}{ Operating range } \\
\hline Valt 㞋e & 28 ta $30 \mathrm{VDC}$ \\
\hline Manual qverride targque & $50 \mathrm{in}-\mathrm{lb}(5.7 \mathrm{Nm}) \mathrm{maximum}$ \\
\hline \multicolumn{2}{|l|}{ Cannectians } \\
\hline Selenaid valve asembly & $\begin{array}{l}\text { mating thread cannects with BACC45FT10- } \\
\text { 5S6 ar equivalent }\end{array}$ \\
\hline Dawnst ream sensing part & $\begin{array}{l}0.5625-18 \text { UNJF-3B threads perMS33649- } \\
06\end{array}$ \\
\hline Cabin pressure part & $\begin{array}{l}0.5625-18 \text { UNJF-3B threads perMS33649- } \\
06\end{array}$ \\
\hline
\end{tabular}

\section{Hasil dan Pembahasan}

Tabel 2. Data Kerusakan Trim Air PRSOV

\begin{tabular}{|c|c|c|c|c|c|c|c|c|c|c|c|c|c|c|c|}
\hline NO & $\begin{array}{c}\text { Part } \\
\text { Number }\end{array}$ & $\begin{array}{c}\text { Bulan/ } \\
\text { Tahun }\end{array}$ & 1 & 2 & 3 & 4 & 5 & 6 & 7 & 8 & 9 & 10 & 11 & 12 & Removal \\
\hline 1 & $3214972-1$ & 2016 & 3 & 0 & 0 & 0 & 2 & 0 & 0 & 0 & 1 & 0 & 1 & 2 & 9 \\
\hline 2 & $3214972-1$ & 2017 & 1 & 1 & 3 & 2 & 1 & 2 & 1 & 0 & 3 & 0 & 1 & 3 & 18 \\
\hline 3 & $3214972-1$ & 2018 & 4 & 1 & 2 & 3 & 8 & 0 & 1 & 5 & 1 & 0 & 4 & 1 & 30 \\
\hline 4 & $3214972-1$ & 2019 & 2 & 2 & 0 & 1 & 2 & 2 & 4 & 2 & 0 & 0 & 0 & 1 & 16 \\
\hline 5 & $3214972-1$ & 2020 & 1 & 0 & 1 & 0 & 0 & 0 & 0 & 2 & 2 & 1 & 0 & 1 & 8 \\
\hline 6 & $3214972-1$ & 2021 & 1 & 0 & 2 & 0 & 0 & 0 & \multicolumn{7}{|c|}{ Jumlah } \\
\hline
\end{tabular}

Kerusakan kompenen Trim Air PRSOV pada salah satu maskapai nasional Indonesia khususnya memiliki pesawat Kerusakan yang terjadi pada komponen Trim Air PRSOV disebabkan oleh kebocoran pada bagain komponen Boeing 737-800 pada periode Januari 2016 sampai dengan Juni 2021 berjumlah 84, yang dimana 13 diantaranya dikarenakan sheduled maintenance. Dibawah ini adalah data kerusakan komponen Trim Air PRSOV pada table 2. sehingga tekanan dan temperature rendah dan cenderung tidak konstan.

Berikut adalah diagram pareto pada tabel 3. Dari data diatas dapat disimpulkan bahwa penyebab kerusakan yang paling sering terjadi pada komponen Trim Air PRSOV adalah kerusakan pada bagian diaphragm, erosi pada bagian ring seal dan shaft seal rusak selama periode penelitian. Adapun perhitungan untuk mencari faktor dominan adalah:

Table 3. Kerusakan pada Trim Air PRSOV

\begin{tabular}{|c|c|c|c|c|}
\hline No & Penyebab Kerusakan & $\begin{array}{l}\text { Frekuensi } \\
\text { Kejadian }\end{array}$ & Presentase & $\begin{array}{c}\text { Kumulatif } \\
(\%)\end{array}$ \\
\hline 1 & Kerusakan pada diaphragm & 32 & 43 & 43 \\
\hline 2 & Erosi pada ring sea! & 17 & 22 & 65 \\
\hline 3 & Shaft seal rusak & 9 & 12 & 77 \\
\hline 4 & $\begin{array}{l}\text { Kebocoran pada actuator } \\
\text { body }\end{array}$ & 6 & 8 & 85 \\
\hline 5 & $\begin{array}{l}\text { Pressure regulator tidak } \\
\text { bisa di acjust }\end{array}$ & 5 & 7 & 92 \\
\hline 6 & $\begin{array}{l}\text { Manual override tidak } \\
\text { berfungsi dengan baik }\end{array}$ & 3 & 4 & 96 \\
\hline 7 & Selenojdyang sudah jelek & 3 & 4 & 100 \\
\hline & Jumlah & 75 & & \\
\hline
\end{tabular}

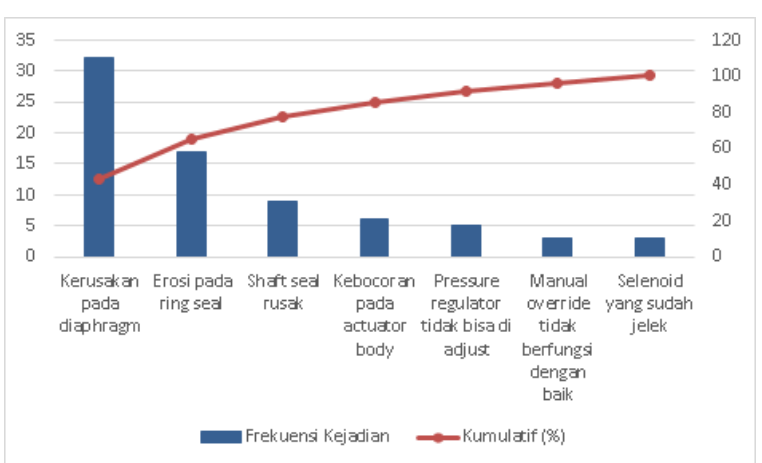

Dari data diatas dapat disimpulkan bahwa penyebab kerusakan yang paling sering terjadi pada komponen Trim Air PRSOV adalah kerusakan pada bagian diaphragm, erosi pada bagian ring seal dan shaft seal rusak selama periode penelitian. Adapun perhitungan untuk mencari faktor dominan adalah:

$\mathrm{K} 1+\mathrm{K} 2+\mathrm{K} 3=80 \%$ (Sesuai Hukum Pareto) 
Jurnal Teknologi Kedirgantaraan, Vol, VII No. 1, Januari 2022, P-ISSN 2528-2778, E-ISSN 2684-9704 https://doi.org/ 10.35894/jtk.v7i1

Maka:

$43 \%+22 \%+12 \%=77 \%$

( $\pm 80 \%)$.

Keterangan:

K1= Kejadian Persentase Tertinggi Pertama

$\mathrm{K} 2=$ Kejadian Persentase Tertinggi Kedua

K3= KejadianPersentase TertinggiKetiga

Dengan mengikuti kaidah pareto lebih difokuskan untuk ketiga kerusakandiatas yang memiliki persentase tertinggi dan diharapkan dapat mengurangi $80 \%$ kerusakan yang terjadi.

Setelah nilai severity, occurance dan detection didapatkan dari kuesioner narasumber, maka dapat dilakukan perhitungan nilai RPN dengan cara melakukan perkalian antara nilai Berdasarkan tabel 4 diatas, maka didapatkan nilai RPN yang terbesar adalah kerusakan pada diaphragm. Diikuti itu kebocoran pada shaft seal dan Erosi pada ring seal. Maka di dapatkan bahwa 3 kerusakan pada Trim Air PRSOV diperlukan tindakan agresifuntuk mengurangi kerusakan yang terjadi severity, occurance dan detection. Kemudian hasil RPN tiap kuesioner narasumber ditambah dengan hasil kuesioner narasumber lain yang kemudian ditotal dan dibagi dengan jumlah kuesioner sehingga mendapatkan rata-rata dari RPN. Nilai RPN tertinggi merupakan indikator resiko tertinggi yang menjadi sasaran utama perbaikan yang harus diselesaikan.

Komponen shop yang berada di PT. GMF Aeroasia sudah memiliki capability untuk memperbaiki komponen Trim Air PRSOV hingga ketahap modifikasi dan overhaul. Kerusakan yang terjadi selama periode penelitian dilakukan hingga tahap repair.

Tabel 4. Nilai Risk Priority Number (RPN)

\begin{tabular}{|c|l|c|c|c|}
\hline NO & \multicolumn{1}{|c|}{ Penyebab Kerusakan } & RPN & Classification & Task Section \\
\hline 1 & Kerusakan pada diaphragm & 398,1 & $\mathrm{MH}$ & Tindakan Agresif \\
\hline 2 & Erosi pada ring seal & 367,0 & $\mathrm{MH}$ & Tindakan Agresif \\
\hline 3 & Shaft seal rusak & 295,1 & $\mathrm{MH}$ & Tindakan Agresif \\
\hline 4 & $\begin{array}{l}\text { Kebocoran pada actuator } \\
\text { body }\end{array}$ & 194,4 & $\mathrm{M}$ & $\begin{array}{c}\text { Tindakan } \\
\text { Secukupnya }\end{array}$ \\
\hline 5 & $\begin{array}{l}\text { Pressure regulator tidak } \\
\text { bisa di adjust }\end{array}$ & 156,6 & $\mathrm{M}$ & $\begin{array}{c}\text { Tindakan } \\
\text { Secukupnya }\end{array}$ \\
\hline 6 & $\begin{array}{l}\text { Manual override tidak } \\
\text { berfungsi dengan baik }\end{array}$ & 113,6 & $\mathrm{M}$ & $\begin{array}{c}\text { Tindakan } \\
\text { Secukupnya }\end{array}$ \\
\hline 7 & Seienoid yang sudah jelek & 104,0 & $\mathrm{M}$ & $\begin{array}{c}\text { Tindakan } \\
\text { Secukupnya }\end{array}$ \\
\hline
\end{tabular}

Table 5. TAT Kerusakan di Shop Component

\begin{tabular}{|c|c|c|c|c|}
\hline No & Shop In & Shop Out & TAT & Reason of Removal \\
\hline 1 & 08 Agustus 2019 & 22 Agustus 2020 & $\begin{array}{c}14 \\
\text { Hari }\end{array}$ & Ring seal erroded \\
\hline 2 & 15 Desember 2019 & 25 Desember 2019 & $\begin{array}{c}10 \\
\text { Hari }\end{array}$ & Diaphragm broken \\
\hline 3 & 23 Januari 2020 & 06 Februari 2020 & $\begin{array}{c}14 \\
\text { Hari }\end{array}$ & Shaft seal broken \\
\hline 4 & 10 Maret 2020 & 24 Maret 2020 & $\begin{array}{c}14 \\
\text { Hari }\end{array}$ & Ring seal erroded \\
\hline 5 & 15 Agustus 2020 & 29 Agustus 2020 & $\begin{array}{c}14 \\
\text { Hari }\end{array}$ & Shaft seal broken \\
\hline 6 & 04 September 2020 & 14 September 2020 & $\begin{array}{c}10 \\
\text { Hari }\end{array}$ & Diaphragm broken \\
\hline 7 & 18 Oktober 2020 & 02 November 2020 & $\begin{array}{c}14 \\
\text { Hari }\end{array}$ & Ring seal erroded \\
\hline 8 & 16 Desember 2020 & 26 Desember 2020 & $\begin{array}{c}10 \\
\text { Hari }\end{array}$ & Diaphragm broken \\
\hline 9 & 24 Januari 2021 & 4 Februari 2021 & $\begin{array}{c}10 \\
\text { Hari }\end{array}$ & Diaphragm broken \\
\hline 10 & 30 Maret 2021 & 13 April 2021 & $\begin{array}{c}14 \\
\text { Hari }\end{array}$ & Shaft seal broken \\
\hline
\end{tabular}

Dari data diatas waktu yang paling lamadalam perbaikan adalah erosi pada ring seal dan shaft seal rusak dikarenakan itu menunjukkan bahwa pengerjaan erosi pada ring seal dan shaft seal rusak diperlukan langkah yang agresif diperlukan kehati-hatian dalam pengerjaannya dan langkah kerja yang dilakukan untuk membuka ring seal dan shaft seal banyak. Maka diperlukan waktu yang lebih lama dari pada kerusakan yang lain. TAT yang dilakukan dilakukan dari tahap testing, disassembly, cleaning, inspection, repair, assembly, final test. Dan waktu 
diatas adalah waktu yang ideal dilakukan, tidak termasuk keterlambatan dikarenakan material yang diperlukan habis atau tidak ada.

\section{IV.KESIMPULAN}

Berdasarkan analisis dan pengumpulan data yang telah dilakukan, didapatkan beberapa kesimpulan sebagai berikut:

1. Kerusakan yang paling sering terjadi pada Trim Air PRSOV adalah 43\% kerusakan pada diaphragm, 22\% erosi pada ring seal, dan $12 \%$ shaft seal rusak.

2. Dengan menggunakan metode FMEA dapat diketahui nilai RPN terbesar terjadi karena kerusakan pada diaphragm dengan nilai 398,1, shaft seal rusak dengan nilai RPN 367 dan erosi pada ring seal dengan nilai RPN 295,1 yang memerlukan tindakan agresif. component shop selama 14 hari kerja dan untuk kerusakan pada diaphragmdilakukan selama 10 hari. TAT tersebut termasuk testing, disassembly, cleaning, inspection, repair, assembly, final test

\section{V.DAFTAR PUSTAKA}

[1] Boeing Company. (2017), Aircraft Training Manual Chapter 21 Air Conditioning, Boeing 737600/700/800/900.

[2] Abiyoga, Dimas (2013). Sistem Pengondisian Udara Pada Pesawat Terbang

[3] Boeing Company. (2017), Component Maintenance Manual
Chapter 21. Temperature Control Valve, Boeing 737600/700/800/900

[4] Faizal, K. \& Palaniappan, D. P. K., 2014. Risk Assessment and Management in Supply Chan, 14(Global Journal Inc. (USA)).

[5] Widianti, Tri dan Himma Firdaus.(2017), Penilaian Resiko Instansi Pemerintas dengan FuzzyFailure Mode and Effect Analysis. LIPI Press: Jakarta.Technology.

[6] Ariani, D. (2003) Manajemen Kualitas Pendekatan Sisi Kualitatif. Ghalia Indonesia: Jakarta.

[7] Matsumoto, T \& Goto, Y. (1975). Reliability Analysis of Catalytic Converter as an Automotive Emission Control System. Michigan:SAE Technical Paper.

[8] Winandi, A., 2012. Reliability Centered Maintenance Pada Pompa, Issue Universitas Indonesia.

[9] Barry Render, Jay Heizer. 2004. Management Mutu Terpadu. Penerbit Salemba 4.

[10] Ishikawa, Khoru. Pengendalian Mutu Terpadu, Bandung: Remaja Rosdakarya, 1985.

[11] Reliability Management."Dashboard Reliablity". https://dashboardreliability.gmf- aeroasia.co.id/. diakses pada1Agustus 2021 pukul 15.10 . 